\title{
Research on Financial Performance Evaluation of Listed Companies in Iron and Steel Industry
}

\author{
Yang Xiaochen, Zhang Hao
}

School of Economics and Management, Jiangsu University of Science and Technology, Zhenjiang, China

Email address:

674307499@qq.com (Yang Xiaochen), haozh168@aliyun.com (Zhang Hao)

\section{To cite this article:}

Yang Xiaochen, Zhang Hao. Research on Financial Performance Evaluation of Listed Companies in Iron and Steel Industry. Science Innovation. Vol. 5, No. 2, 2017, pp. 108-111. doi: 10.11648/j.si.20170502.17

Received: March 19, 2017; Accepted: April 8, 2017; Published: April 12, 2017

\begin{abstract}
To improve the performance level of the iron and steel industry plays an irreplaceable role in the development of the country's industrialization and the development of the national economy. This paper selects 31 listed companies as the research sample. This paper uses DEA to analyze the comprehensive efficiency, pure technical efficiency, scale efficiency and returns to scale from 2011 to 2015. The results show that the efficiency of the iron and steel industry in recent years in general, hoping to improve the scientific and technological innovation, industrial concentration and energy saving and emission reduction.
\end{abstract}

Keywords: Performance Evaluation, Data Envelopment Analysis, Listed Companies, Financial Performance

\section{钢铁制造业上市公司财务绩效评价研究}

杨晓晨, 张浩

经济管理学院, 江苏科技大学, 镇江, 中国

邮箱

674307499@qq. com (杨晓晨), haozh168@aliyun. com(张浩)

摘要：提高钢铁行业的绩效水平对国家的工业化发展以及国家经济的发展发挥着不可替代的重要作用, 本文选择中国 31家钢铁上市公司作为研究样本。使用DEA对2011年到2015年从综合效率、纯技术效率、规模效率和规模报酬展开分析。 结果表明：钢铁行业近年来的效率一般，希望从科技创新、产业集中度和节能减排方面进行改进。

关键词: 绩效评价, 数据包络分析, 钢铁上市公司, 财务绩效

\section{1. 引言}

钢铁业作为国民经济发展的基础行业之一，上游连接 着矿物、煤炭等采掘基础行业,下游衔接着建筑、房地产、 交通运输、机械制造等重要产业，对国家的工业化发展以 及国家经济的发展发挥着不可替代的重要作用, 也是一个 国家综合发展实力重要标志。钢铁业的发展水平直接影响 着国民经济的发展, 近年来, 随着发展循环经济, 调整产 业结构, 走可持续发展道路的发展战略的提出, 钢铁企业
也积极的响应国家的号召, 积极的调整产业结构, 合理的 配置资源, 减少浪费, 促进企业的转型与更好的发展。作 为钢铁业领先企业的上市公司, 更是如何更好的提高企业 的绩效, 也成为了企业发展过程中需要解决的重点和难点。

因此, 在这样的背景下, 本文将使用DEA方法对钢铁 行业上市公司进行 2011年-2015年的财务绩效评价, 希望 通过DEA方法的分析找出企业中存在的问题和不足的地方, 并对此提出相应的改进方法, 为上市公司以后的发展提供 一定的参考建议。 


\section{2. 文献综述}

国外关于绩效评价的研究开始于19世纪中期, 在这个 时候, 企业的管理制度以及市场形态也开始步入正轨, 企 业的绩效评价也随之开始发展, 逐步完善。国外关于绩效 评价的实证研究也有很多, 例如Jung Woo Kim使用随机前 沿模型研究了 52 家钢铁企业的技术效率问题, 并对影响技 术效率的因素进一步展开了分析 [1]。Deborah Ageostino 等详细的介绍了平衡计分卡在企业绩效评价过程需要注 意的问题以及对结果的影响 [2]。DerylNorthcott 等将绩 效评价的方面应用到了对董事会成员绩效的评价, 以及构 建出整个的董事会成员的绩效评价体系 [3]。Konstaninos J Liapis 等将绩效评价应用到房地产项目的评价上面, 并 结合房地产项目的特点, 构建了一套完成绩效评价体系, 对于房地产项目的评价具体现实意义 [4]。Susanne G. Scott 等提出了金字塔型的绩效评价体系, 该体系着重 强调企业的战略在企业中的作用, 实现了企业绩效评价和 企业战略之间的衔接, 为企业战略发展的实现奠定了基础 [5]。

虽然中国对于绩效评价研究起步较晚, 但是随着中国 经济的不断发展, 企业管理者对于提高企业绩效的需求, 目前, 也已经有许多学者进行可绩效评价方面的研究并取 得了一定的成果。对于中国钢铁企业绩效的研究, 不同的 学者选择了不同的方法, 包络平衡计分卡法, 层次分析法、 杜邦分析法以及构建数据模型等方法 [6-9], 在这些方法 中, 许多学者使用数据包络分析 (DEA) 方法对企业进行 绩效评价分析。刘彦平 [10], 李尽法 [11]、李向前 [12] 等使用DEA方法和Malmquist指数原理相结合的方法, 分别 对中国上市钢铁行业2001-2006和2006-2009年的数据进 行了分析, 并对改进企业的经营效率提出了改进建议。韩 晶 [13]将DEA和TOBIT相结合, 采用两步法对中国的钢铁企 业进行了生产效率的分析, 结果表明中国钢铁业技术效率 低下, 并且东部地区的企业技术效率明显高于西部地区的 企业, 笔者根据分析结果指出提高技术效率是钢铁企业提 高绩效的关键。

\section{3. 研究设计与数据处理}

\section{1. DEA样本选择}

根据《上市公司分类指引》的划分标准和说明, 选择 主营业务为钢铁行业的上市公司作为本文的研究样本企
业, 因为此次研究的区间为2011年到2015年, 因此剔除掉 了2011年之前上市的公司或者是在2015年之前退市的公 司。剔除掉了标有ST标志的公司, 因为这些公司的经营业 绩不具有可比性。为了数据的有可获得性, 剔除掉了数据 不可收集的公司, 最后选取了 31 家钢铁上市公司 2011 年 -2015年的数据。

\section{2. DEA评价指标选择}

综合考虑上市公司财务报表中可获得的指标数据以 及以往学者对于评价企业绩效指标的选择情况, 本文选择 总资产、主营业务成本和职工人数作为输入指标, 选择主 营业务收入、净利润和每股收益作为输出指标。

\section{3. 数据来源与处理}

上市公司财务报表数据对外公开, 并且可获得性和准 确性都很高, 因此本文选择从上市公司公布的财务报表中 收集数据, 文中所收集的31家钢铁上市公司2011-2015年 的数据来源如下：上市公司年报和腾讯证券。

在进行数据分析之前需要对数据进行处理, 主要包括 剔除价格影响和无量纲化处理。剔除价格影响是指将总资 产、主营业务成本、净利润和主营业务收入转化为 2011 年的不变价。无量纲化处理是为消除数据由于单位不同所 带来的不能进行比较的问题, 以及消除数据中存在负值的 情况, 具体的处理方法如下所示:

设 $a_{j}=\max Z_{i j}\left(a_{j}\right.$ 为第 $i$ 项指标的最大值 $), b_{j}=m i n Z_{i j}$ ( $b_{j}$ 为第 $i$ 项指标的最小值),

$$
\text { 则 } Z_{i j}=0.1+0.9 \times \frac{Z_{i j}-b_{j}}{a_{j}-b_{j}} \text { 。由此处理之后得到处理之 }
$$

后的数据以便DEA数据的处理分析。

\section{4. 实证分析}

\section{1. 综合效率分析}

综合效率是能够反应企业的资源配置, 以及资源的使 用效率的综合性指标, 综合效率=纯技术效率 $\times$ 规模效率, 当综合效率等于 1 , 说明企业处于综合效率有效状态, 位 于有效生产前沿, 反之则是无效状态。将综合效率按综合 效率 $=1 、 0.95 \leqslant$ 综合效率 $<1 、 0.90 \leqslant$ 综合效率 $<0.95$ 和 综合效率 $<0.90$ 区间分类，具体分类情况如下表所示:

表1 2011-2015年31家钢铁上市公司综合效率区间分布表。

\begin{tabular}{|c|c|c|c|c|c|c|c|c|c|c|}
\hline \multirow{2}{*}{ 区间分布 年份 } & \multicolumn{5}{|c|}{ 样本个数（个） } & \multicolumn{5}{|c|}{ 所占比例（\%） } \\
\hline & 2011 & 2012 & 2013 & 2014 & 2015 & 2011 & 2012 & 2013 & 2014 & 2015 \\
\hline 综合效率=1 & 13 & 10 & 8 & 8 & 9 & 35.48 & 32.26 & 25.81 & 25.81 & 29.03 \\
\hline $0.95 \leqslant$ 综合效率 $<1$ & 16 & 15 & 22 & 22 & 12 & 58.06 & 48. 39 & 70.97 & 70.97 & 38.71 \\
\hline $0.90 \leqslant$ 综合效率 $<0.95$ & 2 & 5 & 1 & 1 & 8 & 6.45 & 16. 13 & 3.23 & 3.23 & 25.81 \\
\hline 综合效率 < 0.90 & 0 & 1 & 0 & 0 & 2 & 0.00 & 3.23 & 0.00 & 0.00 & 6.45 \\
\hline
\end{tabular}

从上表中可以看出, 在2011-2015年中, 综合效率 $\geqslant$ 0.95 的公司所占样本的比例分别为 $93.55 \%$ 、 $80.65 \%$ 、 $96.77 \% 、 96.77 \%$ 和 $67.74 \%$, 说明钢铁行业整体的综合效率
较高, 但是在 2012 年和 2015 年出现了降低, 特别是 2015 年所占比例降低到了 $67.74 \%$, 说明这一年中钢铁行业的经 营状况不良。在 5 年中, 综合效率等于 1 的公司数量分别为 
$11 、 10 、 8 、 8$ 和 9 , 所占比例为 $35.48 \% 、 32.26 \% 、 25.81 \%$ 、 $25.81 \%$ 和 $29.03 \%$, 可以看出, 由于近几年来产能过剩影响, 综合效率为有效的企业呈现出下降的趋势, 但是总体来看, 综合效率有效的企业占 $30 \%$ 左右。综合效率 $<0.90$ 的企业 只在 2012 年和 2015 年出现, 说明在这两年中, 钢铁行业公 司的经营效率不佳。

\section{2. 纯技术效率分析}

纯技术效率是指在不考虑规模效率的情况下, 企业由 于受管理和技术等影响因素而产生的生产效率，当纯技术 效率等于 1 时, 说明公司在管理和技术水平上达到了有效 的状态。反之, 当纯技术效率小于 1 , 说明企业的纯技术 效率无效, 还存在有待提高的地方。根据纯技术效率的变 化情况, 将钢铁上市公司的综合效率变化分为六类。

表2 2011-2015年31家钢铁上市公司纯技术效率变化情况表。

\begin{tabular}{|c|c|c|c|}
\hline 类别 & 数量 $($ 个) & 比例 $(\%)$ & 企业名称 \\
\hline 稳定型 & 7 & 22.58 & 宝钢股份、酒钢宏兴、久立特材、金洲管道、方大特钢、物产中拓、常宝股份 \\
\hline 递增型 & 0 & 0 & \\
\hline 递减型 & 4 & 12.90 & 三钢闽光、西宁特钢、本钢板材、重庆钢铁 \\
\hline 先增后减型 & 2 & 6. 45 & 首钢股份、武钢股份 \\
\hline 先减后增型 & 7 & 22.58 & 大冶特钢、太钢不锈、鲁银投资、杭钢股份、新兴铸管、沙钢股份、凌钢股份 \\
\hline 波浪型 & 11 & 35.48 & $\begin{array}{l}\text { 河钢股份、抚顺特钢、柳钢股份、新钢股份、鞍钢股份、南钢股份、山东钢铁、安阳钢铁、华菱 } \\
\text { 钢铁、马钢股份、包钢股份 }\end{array}$ \\
\hline
\end{tabular}

从上表的变化情况表可以看出, 31家钢铁上市公司在 2011-2015年期间，纯技术效率稳定型的公司有7家，包括 宝钢股份、酒钢宏兴、久立特材、金洲管道、方大特钢、 物产中拓和常宝股份, 占样本 $22.58 \%$, 这些公司纯技术效 率位于生产前沿, 公司在管理和技术投入方面, 产出达到 有效。和综合效率一样, 31家公司中没有为递增型公司, 说明钢铁行业在这 5 年的发展当中, 除了 7 家纯技术效率稳 定的公司，没有公司在纯技术效率方面呈现递增的情况。 递减型公司有 4 家, 分别为三钢闽光、西宁特钢、本钢板 材、重庆钢铁, 占总样本的 $12.90 \%$, 这6家公司纯技术效
率在2011-2015不断减少，说明企业在管理和技术的方面 存在问题, 需要改进管理和提高技术, 以此来提高企业的 纯技术效率。

\section{3. 规模效率与规模报酬分析}

规模效率是指由于企业规模而影响的生产效率, 当规 模效率等于 1 时, 说明企业规模已经达到, 规模效率有效。 当规模效率小于 1 时, 说明的企业规模效率无效, 企业需 要改进规模。

表3 2011-2015年31家钢铁上市公司规模报酬频数统计表。

\begin{tabular}{|c|c|c|c|c|c|c|c|c|c|c|}
\hline \multirow{2}{*}{ 规模报酬 } & \multicolumn{5}{|c|}{ 样本个数（个） } & \multicolumn{5}{|c|}{ 所占比例 (\%) } \\
\hline & 2011 & 2012 & 2013 & 2014 & 2015 & 2011 & 2012 & 2013 & 2014 & 2015 \\
\hline 不变 & 13 & 14 & 14 & 12 & 11 & 41.94 & 45.16 & 45.16 & 38.71 & 35.48 \\
\hline 递减 & 8 & 9 & 9 & 12 & 15 & 25.81 & 29.03 & 29. 03 & 38.71 & 48. 39 \\
\hline 递增 & 10 & 8 & 8 & 7 & 5 & 32.26 & 25.81 & 25.81 & 22.58 & 16. 13 \\
\hline
\end{tabular}

从表4-10中可以看出，31家公司在5年中，规模报酬 处于不变的情况的企业的数量变化不大, 从2011年到2012 年增加了 1 家, 从2014年和 2015 年分别减少了 2 家和 1 家, 所占比例平均在 $41 \%$ 左右。规模报酬递减的公司数量呈现 出了逐年增加的趋势，从2011年的8家增加至2015年的15 家, 所占样本比例, 也从 $25.81 \%$ 增加至 $48.39 \%$, 说明大部 分企业的生产规模过大，出现了产能过剩的情况。相对而 言, 规模报酬递增的公司数量是逐年递减的趋势, 从2011 年的 10 年减少到 2015 年的 5 家，所占的比例也从 $32.26 \%$ 减 少到 $16.13 \%$, 企业数量减少了一半。

\section{5. 政策与建议}

通过使用DEA方法对 31 家钢铁上市公司绩效分析，对 钢铁行业的发展提出以下的几点建议:

(1) 加大科研投入, 培养创新能力, 提高核心竞争力
中国目前的钢铁企业的发展, 应该摒弃重数量不重质 量的观点, 企业应该重视产品技术研发的投入, 至少应该 拿出企业销售利润的 $2 \%$ 投入到研发当中, 只有在不断的改 进产品的功能和质量, 才能不被市场和消费者抛弃, 如果 要想追赶上一流的企业, 更需要逐年增加科研经费的投入。

(2) 推进钢铁企业兼并重组, 提高产业集中度

规模效率是影响钢铁企业效率的一个重要的因素, 通 过企业之间的兼并重组，整合优质的资源，扩大企业的规 模, 可以享受规模经济给企业带来的优势。国外许多优秀 的大型企业都是通过合并方式而来, 这种方式可以有效的 提高产业集中度。

（3）落实节能减排制度，淘汰落后产能

近年来, 中国大力的提倡节能减排, 使用清洁能源, 钢铁行业更是应该积极落实国家的政策, 使用新清洁能源 替代原有的高污染的能源, 不断的改进企业的生产技术, 降低 “三废” 污染物的排放, 从粗放型的增长模式逐渐向 追求高质量和低污染的集约型发展。 


\section{6. 结论}

总体来说, 近几年来, 我国的钢铁行业发展迅速, 在 钢铁的产量, 生产技术, 企业的规模以及产业集中度方面 有了一定的提高, 但是仍然存在着许多的问题, 如企业的 技术创新能力不够, 产业结构不够合理, 产业的集中程度 有待进一步提高以及高附加值的产品较少。

通过上市公司年报、腾讯证券、上海证券交易所和深 圳证券交易所收集数据并进行预处理, 使用DEAP2. 1软件 进行数据的处理, 并对我国钢铁上市公司进行输入输出指 标描述性分析、综合效率分析、纯技术效率分析、规模效 率分析、规模报酬分析和分区域平均效率分析。评价结果 表明:

（1）在描述性分析方面，31家钢铁上市公司的总资 产均值呈现出逐年递增的趋势, 主营业务成本、主营业务 收入和职工人数的均值都呈现出减少的趋势, 净利润和每 股收益在2012年和 2015 年下降, 说明钢铁行业处于发展的 状态, 但是在2015年, 整个行业情况不景气。

（2）在综合效率方面，钢铁行业整体效率一般，在 2011-2015年中, 平均每年有 $30 \%$ 左右的企业位于生产前沿 水平, 剩余的 $70 \%$ 左右的企业综合效率有待改善。5年中保 持综合效率有效的企业只有五家, 分别为宝钢股份、久立 特材、方大特钢、物产中拓和常宝股份。纵向比较发现, 综合效率在2012年和2015年出现了下降现象, 2015下降幅 度很大。

（3）纯技术有效性表现良好, 在 5 年中纯技术有效的 企业数量变化不大, 约占 $40 \%$ 左右, 并且有 7 家企业连续 5 年处于纯技术有效状态。在规模报酬方面, 经过近几年的 结构调整, 以及扩大企业的规模, 淘汰掉劣质的产能, 规 模效率有所改善, 在 5 年中有 5 家企业保持规模报酬不变的 情况, 大部分的企业向规模报酬不变或者规模报酬递减方 面转变。

（4）在分区域比较分析方面，发现中部地区的综合 效率和纯技术效率都高于其他的三个区域, 西部地区在 2013年前在综合效率和纯技术效率方面均仅低于中部地 区, 但是在2013年后位于四个区域的最差位置, 东北地区 和中部地区在 2013 年后相差不大。

最后, 在使用DEA进行钢铁上市公司绩效分析结果的 基础上, 结合中国的钢铁发展状态, 提出以下建议: 加大 科研投入, 培养创新能力, 提高核心竞争力。推进钢铁企 业兼并重组, 提高产业集中度。落实节能减排制度, 淘汰 落后产能。加强人员管理, 提高企业内部管理水平和加大 中西部地区钢铁企业的支持。

\section{参考文献}

[1] Jung Woo Kim, JeongYeonLee. Technical efficiency in the iron and steel industry: A StochasticFrontier Approach. East-West center for working papers, 2005, (75) : $1-27$.

[2] Deborah Agostino, Michela Arnaboldi. How the BSC implementation process shapesitsoutcome [J]. International Journal of Productivity and performance Management, 2011, 60 (2) : 99-114.

[3] DerylNorthcott, Janine Smith. Managing performance at the top: a balanced scorecard for boards of directors $[\mathrm{J}]$. Journal of Accounting \& Organizational Change, 2011, 7 (1) : 33-56.

[4] Konstaninos J Liapis, Manolis S. Christofankis, Harris G P. A new evaluation procedure in real estate projects [J]. Journal of Property Investment \& Finance, 2011. 29 (3) : 280-296.

[5] Susanne G. Scott, Waltei0. Einstein. Strategic performance appraisal in team-based organizations: One size does not fit all [J]. Academy of Management Executive, 2010, (5) : 107-116.

[6] 蔡晓春, 邹克. 基于DEA-Malmquist的钢铁行业上市公司能 源效率研究 $[J]$. 统计与信息论坛, 2012 (8) : 90-98。

[7] 董晓东, 沈玉志. 我国重点钢铁企业效率提升的实证研究 [J]．统计与决策，2013(13):126-129。

８］张庆芝, 何枫, 雷家啸. 循环经济下我国钢铁企业技术效 率与技术创新研究 [J]. 研究与发展管理, 2014 (12) :2-8. 鍶。

[9] 刘秉镶, 林坦, 刘玉海. 规模和所有权视角下的中国钢铁 企业动态效率研究 [J]. 中国软科学, 2010 (1) : 150-157. 克古 俥。

[10］李尽法, 吴育华, 潘海生. 基于Malmquist 指数的钢铁企业 效率测度分析 [J]. 北京理工大学学报 (社会科学 版), 2008, (6):65一68。

[11] 孙海刚钢铁上市公司的技术效率与企业绩效一一基于我国 钢铁产业竞争力的提升 $[\mathrm{J}]$. 经济管理, 2009, (7): 65-72。

[12] 李向前我国钢铁业上市公司经营效率评价及影响因素分析 [D]. 硕士学位论文. 重庆: 重庆大学, 2009年。

[13] 韩晶. 中国钢铁业上市公司的生产力和生产效率一一基 DEA-TOBIT两步法的实证研究 [J]. 北京师范大学学报 (科 学社版), 2008, (1) : 119-126。 